\title{
WASCON 2018: No Cradle, No Grave-Circular Economy into Practice
}

\author{
Carlo Vandecasteele ${ }^{1} \cdot$ John Heynen ${ }^{2} \cdot$ Chi Sun Poon ${ }^{3}$
}

Published online: 31 October 2020

(c) Springer Nature B.V. 2020

The 10th International Conference on the Environmental and Technical Implications of Construction with Alternative Materials "WASCON 2015: No Cradle, no Grave-Circular Economy into Practice" took place from 6 to 8 June 2018, in the Tampere-hall, Tampere, Finland. It was organized by RIL, the Finnish Association of Civil Engineers together with ISCOWA. WASCON is the reference international conference on the use of alternative materials in construction. It has been held every 3 years since 1991 and provides a forum for exchange of ideas and current research on the use of waste, industrial by-products and other recycled materials in construction. The importance of this subject is proven by the fact that construction of buildings accounts in the EU for about half of the extracted materials and for $25-30 \%$ of the waste generated. Moreover, environmental pressures arise at all stages of the construction life cycle, including the manufacturing of construction products, physical construction, use of buildings, renovation and the management of waste.

213 people from 28 countries and from 4 continents participated in the 3-day conference and represented private companies, research and technological centers, universities, professional associations and administrations. The program consisted of 4 plenary lectures, 76 oral presentations, and 24 posters. In addition 12 workshops were organized.
Already from the start of the series, the WASCON conferences promoted circular economy 'avant la lettre', and most of the material presented at the previous WASCON conferences was in line with the circular economy. With the subtitle "No Cradle, no Grave-Circular Economy into Practice" we wanted to state explicitly that WASCON is not just about recycling and recovery of waste, but gives e.g. also attention to reuse of old constructions and to design aspects that aim at extending the lifetime of buildings, or at preventing building waste, all this aiming at a circular economy.

In this special issue nine papers selected from those presented at the conference are given. The first five are about the production, use and environmental impact of building materials from MSWI bottom ash. The other four are about alternative materials (earth, ferrochrome slag, sheet metal waste, glass) in construction or construction materials.

More information about ISCOWA and WASCON2018 can be found at www.iscowa.net.

Publisher's Note Springer Nature remains neutral with regard to jurisdictional claims in published maps and institutional affiliations.

Carlo Vandecasteele

carlo.vandecasteele@kuleuven.be

Chi Sun Poon

cecspoon@polyu.edu.hk

1 Department of Chemical Engineering, University of Leuven, Heverlee, Belgium

2 ISCOWA/Netherlands Enterprise Agency (RVO), Utrecht, The Netherlands

3 Dept of Civil and Environmental Engineering, The Hong Kong Polytechnic University, Hung Hom, Hong Kong 